\title{
PROCESO DE ADQUISICIÓN DE LA NATURALEZA COMPOSICIONAL DEL ASPECTO EN EL ESPAÑOL COMO LENGUA EXTRANJERA: EL RECONOCIMIENTO DE LA COLABORACIÓN DE LOS MARCADORES ASPECTUALES CADA + SN y DURANTE + SN EN LA COMPOSICIÓN DEL MODO DE ACCIÓN DEL ENUNCIADO
}

\author{
LOURDES GÜELl MASACHS \\ Universitat Autònoma de Barcelona \\ Lourdes.guell@uab.cat \\ Lulaguell@gmail.com
}

\begin{abstract}
RESUMEN
El objetivo de este trabajo es estudiar el reconocimiento de la incidencia de los marcadores léxicos temporales y aspectuales como Durante + SN temporalizado o Cada + SN temporalizado en la composición aspectual del enunciado a lo largo del proceso de adquisición de esta categoría funcional en el español como lengua extranjera (ELE). Para alcanzar dicho objetivo, adoptamos una concepción actualizada del aspecto gramatical (vid. Verkuyl, 1972, 1989, 1990, 1993; Smith, 1991, entre otros). Nos proponemos, además, valorar la conocida como Hipótesis del tiempo defectivo que, sin lugar a dudas, constituye la hipótesis con mayor vitalidad sobre el proceso de adquisición del tiempo y el aspecto en lenguas segundas desde su aparición en los años 70 del siglo pasado (vid. Brown, 1973, Villiers \& de Villiers, 1973, Dulay $\&$ burt, 1973, Krashen, 1977, entre otros).

Se valora además cómo evolucionan las Interlenguas ( $\mathrm{IL}_{\mathrm{s}}$ ), qué mecanismo activan los aprendices de ELE en cada una de las etapas de su desarrollo hacia la lengua objeto (LO). Se intenta comprobar si se observa algún cambio significativo en algún punto del proceso.
\end{abstract}

\section{ABSTRACT}

The aim of this work is to study the recognition of the influence of the lexical markers of time and aspectuality as Durante $+S N$ temp. or Cada + SN temp. throughout the process of acquisition of this functional category in Spanish as a second language (ELE). In order to reach this objective, we adopted an updated conception of aspectuality (see Verkuyl, 1972, 1989, 1990, 1993; Smith, 1991). We estimate to validity of Hypothesis of the defective time (vid. Browns, 1973, Villiers \& of Villiers, 1973, Dulay \& Burt, 1973, Krashen, 1977).

It is valued how Interlenguages (IL) develop, what mechanism learners use in every step of the development towards object language (LO). We also try to check if there is any signifiant change at any point/step of the process. The study of the successive IL has been realised essentially through the systematic contrast to the non-native output with those productions from a group of native speakers, considered as a checking group. 
El estudio de las sucesivas IL se ha realizado fundamentalmente a través del sistemático contraste de las producciones no nativas con las de un grupo de nativos que, habiéndose sometido a las mismas pruebas que los aprendices, se considera el grupo de control.

PALABRAS CLAVE: Español como lengua extranjera, temporalidad, aspectualidad, interlengua, morfología flexiva del verbo.
KEY WORDS: Spanish as a second language, temporality, aspectuality, interlanguage, tense.

\section{Introducción}

Pocas hipótesis como la de la Primacía del aspecto sobre el tiempo, también denominada Hipótesis del tiempo defectivo ${ }^{1}$, han sido y siguen siendo tan recurrentes en la bibliografía sobre adquisición de la flexión verbal no sólo de la primera lengua sino también de lenguas segundas. No por ello es ajena, no obstante, a revisión, como la que pretendemos llevar a cabo en este trabajo $^{2}$. Aquí nos proponemos valorar concretamente el reconocimiento de la incidencia de los marcadores aspectuales cada + SN temp. y durante + SN temp. en el valor aspectual del predicado en las IL de aprendices adultos de español como lengua extranjera (ELE); en otros términos, la participación de dichos marcadores en la organización composicional del aspecto.

En el decenio de los setenta del siglo pasado, el afán por hallar pautas universales que pudieran explicar el proceso de adquisición de la flexión verbal, junto al reciente descubrimiento de la categoría aspecto en las lenguas eslavas ${ }^{3}$,

1 Esta hipótesis defiende que, en las primeras fases del proceso de adquisición de las formas y funciones del paradigma verbal, tanto los niños como los aprendices adultos se guían por criterios aspectuales y no temporales.

2 En trabajos nuestros anteriores hemos matizado dicha hipótesis (vid. Güell, 2008 y 2009). En ellos se estudia, en concreto, el reconocimiento de la incidencia del valor $[ \pm$ definido] del argumento interno del verbo y el de la partícula terminativa "se", respectivamente, sobre el valor aspectual del enunciado. Los resultados ponen de manifiesto que, hablando de forma estricta, en el proceso de adquisición de las funciones de los pretéritos indefinido e imperfecto la temporalidad precede al aspecto propiamente dicho. Tenemos en cuenta los resultados de dichos trabajos para matizar las hipótesis que nos proponemos someter a comprobación en este trabajo (vid. \& 4 infra).

3 Según se defiende en algunos estudios diacrónicos (cfr. Meillet, 1926; Burger, 1949; Cretella, 1953, por ejemplo), la oposición latina entre las formas del infectum y las del perfectum acabó siendo redundante con respecto a las oposiciones temporales. Es probable que esta debilitación del aspecto en favor del tiempo influyera en la desatención de los tratados gramaticales por la categoría aspecto. El interés por el aspecto en el verbo no se recupera hasta el s. XVII y, cuando se produce, no es en relación con la tradición gramatical 
llevó a los estudiosos a fijar la atención en la correspondencia entre, por un lado, las formas de la flexión del verbo y, por otro, el valor aspectual de la entrada léxica del verbo. Las primeras investigaciones sobre el tema que nos ocupa ponen de manifiesto la secuencialidad en la aparición de las marcas morfológicas en la adquisición de la Ll (Brown, 1973; Villers \& de Villers, 1973) y en la IL (Dulay \& Burt, 1974a, 1974b; Krahen, 1977 o Makino, 1980). Investigaciones posteriores (el estudio pionero de Bronckart \& Sinclair (1973), así como los de de Lemos, 1975, Antinucci \& Miller, 1976; Aksu, 1978; Bloom, Lifter \& Hafitz, 1980; Jackobsen, 1986, entre otros, que analizan el comportamiento infantil de distintas Ll -portugués, italiano, turco, inglés y peruano-) muestran que la aparición de las marcas morfológicas refleja una clara tendencia distributiva guiada por el valor léxico-semántico del verbo ${ }^{4}$.

Ahora bien, visto desde la actualidad, los trabajos en esta línea parten de una concepción simplificada de la categoría aspecto $^{5}$. En efecto, el hecho de

greco-latina, sino a través de la lingüística eslava. En un trabajo sobre datos del checo (y posteriormente en otros sobre el ruso y otras lenguas eslavas), se puso de manifiesto la necesidad de introducir el aspecto como eje de ordenación de las formas verbales de tales lenguas, al observarse una correspondencia directa entre el uso de los procedimientos morfológicos y léxicos y, entre éstos y la expresión de los modos "subjetivo" y "objetivo" de concebir el acontecimiento expresado por el verbo. De acuerdo con ello, se definieron las formas verbales como la manera de "ver" la acción verbal: cualquier "acción" se puede "ver" bien como acabada, bien como no acabada. Además, la primera de estas dos posibles perspectivas es susceptible de adoptar el valor "concluido" o el valor "resultativo" (valores derivados de "acabado"), formas todas ellas agrupadas bajo el término "aspecto perfectivo"; mientras que la segunda, denominada "aspecto imperfectivo", admite como valores aspectuales subsidiarios la duración y la iteración. Esta correspondencia directa que se observa en las lenguas eslavas no se reconoce, no obstante, en todas las lenguas. Probablemente, como indica Rojo (1974: 128-129), muchos de los problemas en torno al aspecto derivan de que la introducción (o reintroducción) de la noción de aspecto, "incluso el término (traducción del ruso vid)", proceda de la lingüística eslava.

$4 \quad$ Los resultados de éstos y otros trabajos similares se adoptan como argumentos para defender que la oposición aspectual [ \pm perfectivo] es una propiedad universal del lenguaje, como ya se había propuesto en Bickerton (1975), Comrie (1976) o Givón (1982), entre otros. En relación con los estudios sobre adquisición de la morfología flexiva del verbo, estos resultados constituyen el argumento que lleva a formular la "Hipótesis de la primacía del aspecto sobre el tiempo" (vid .n. 1). Influidos, además, por la vitalidad de la Hipótesis de $\mathrm{L} 1=\mathrm{L} 2$, varios estudios sobre el proceso de adquisición de la L2 se fijan como objetivo comprobar si la Hipótesis de la primacía del aspecto sobre el tiempo puede describir el desarrollo de las IL hacia la LO. Nos referimos a investigaciones como las de Kumpf (1982), Flashner (1982), Rothstein (1985), Economides (1985), entre otros.

5 No es de extrañar, dado que el aspecto constituye una de las partes más confusas de cualquier tratado gramatical. Junto a esta valoración, que ya se ha convertido en un lugar común, también es habitual afirmar, como hace Rojo (1990: 31), que "No es fácil encontrar una categoría gramatical en la que las discrepancias entre los lingüistas sean tan llamativas" (además, cfr. Keniston, 1936; Cerny, 1970; Rallides, 1971; Rojo, 1974, 1988; Lyons, 1977; 
que se observe cierta tendencia a seleccionar tiempos verbales perfectivos e imperfectivos para presentar verbos léxicamente perfectivos e imperfectivos, respectivamente, no se puede considerar un argumento a favor de la primacía del aspecto sobre el tiempo. Y ello es así porque si bien las propiedades aspectuales contenidas en la entrada léxica del verbo participan en la composición del aspecto, no son por sí mismas el aspecto (vid. Verkuyl, 1972, 1989, 1990, 1993; Smith, 1990, entre otros).

Aquí concebimos el aspecto como una categoría gramatical de carácter composicional en la que participan factores lingüísticos de distinta naturaleza: las propiedades aspectuales contenidas en la entrada léxica del verbo así como en la de otras piezas léxicas del predicado, ciertas propiedades sintagmáticas del sujeto y del argumento interno del verbo, la presencia en el predicado de marcadores temporales y aspectuales (como cada $+\mathrm{SN}$ o durante + $S N$, unidades en las que nos centramos en este trabajo), la aparición de partículas terminativas del tipo de se en SE comió tres caramelos, por ejemplo, o la morfología flexiva del verbo, por citar sólo algunos de ellos.

En la línea de Smith (1990), distinguimos entre la información aspectual contenida en las unidades léxicas y la que se manifiesta por medio de la flexión verbal. La primera articula composicionalmente el modo de acción del predicado y la segunda constituye la presentación gramatical del acontecimiento expresado por el predicado "desde una perspectiva y un enfoque concretos, como la lente de una cámara" (Smith, 1991: 7). Estas dos manifestaciones gramaticales (la léxica y la morfológico-verbal) concurren para componer el aspecto de un predicado. De acuerdo con ello, como ya hemos comentado, el hecho de que en la lengua infantil o en las IL, la aparición de los morfemas flexivos del verbo se vea guiada por las propiedades aspectuales contenidas en la entrada léxica del verbo no supone la adquisición de la categoría aspecto. Estos resultados reflejan más bien que los niños y aprendices adultos se apoyan en el léxico para organizar sus gramáticas infantiles y no nativas. Parece claro que para poder hablar de la primacía del aspecto sobre el tiempo no podemos limitarnos a valorar la correspondencia entre las formas de la conjugación y las propiedades relacionadas con el aspecto contenidas en la entrada léxica del verbo. Para ello es necesario adoptar una unidad superior al verbo que permita valorar si los aprendices reconocen y en qué

Tedeschi \& Zaenen, eds., 1981). En efecto, a pesar de que los fenómenos relacionados con el aspecto han sido objeto de estudio, de forma generalizada, desde Aristóteles hasta la actualidad, no se ha alcanzado el necesario acuerdo sobre cuestiones tan básicas como son su definición, cuál es la propiedad que permite distinguir entre las posibles clases aspectuales o cuáles son los fenómenos en los cuales está implicado el aspecto y no otra categoría gramatical. Para una relación fundada de las discrepancias en torno al aspecto, cfr. Lyons (1977). 
orden la colaboración de las diversas unidades en la composicionalidad del "modo de acción" del predicado o componente léxico del aspecto; por otro lado, debería comprobarse si esta unidad "concuerda" con las formas de la conjugación; de esta forma se podría establecer si realmente el criterio que guía la aparición de la morfología flexiva del verbo es o no el aspecto.

Consideramos, además, que la información aspectual que se manifiesta por medio de la morfología flexiva del verbo puede concordar o no con el modo de acción del predicado, donde por "concordancia" entendemos coincidencia de las respectivas informaciones aspectuales ${ }^{6}$. Ahora bien, debemos tener en cuenta que a diferencia de la concordancia en número y persona entre el verbo y el SN sujeto, que también se manifiesta por medio de la morfología flexiva del verbo, la concordancia aspectual entre un tiempo verbal y el "modo de acción" del predicado no es obligatoria. La falta de coincidencia entre el "modo de acción" del predicado y la información aspectual contenida en los tiempos verbales produce, no obstante, una interpretación derivada del acontecimiento expresado por el predicado: en Juan se dormía y en Juan cantaba una canción por ejemplo, el imperfecto lleva a una lectura iterada de los acontecimientos [Juan dormirse] ${ }^{7}$ y [Juan cantar una canción], que contrasta por ello con las de Juan se durmió y Juan cantó una canción.

En este trabajo, adoptamos este marco de observación para valorar el reconocimiento del papel que desempeña la presencia de marcadores temporales y aspectuales en la composición del valor aspectual de todo el enunciado.

A continuación, presentamos la información acerca de los informantes, las pruebas de obtención de datos, y las hipótesis que sometemos a comprobación.

\section{Los informantes}

Para este estudio, contamos con dos grupos de informantes: uno formado por aprendices de ELE y el otro por hablantes nativos, que constituyen el grupo de control. A continuación describimos de forma general estos dos grupos de informantes.

6 Así, por ejemplo, por el modo de acción perfectivo de los predicado [Juan dormirse] o [Juan cantar una canción], el indefinido y no el imperfecto es el tiempo verbal que concuerda aspectualmente con dichos predicados (Juan se durmió y Juan cantó una canción, respectivamente). El modo de acción perfectivo de [Juan dormirse] está determinado por la presencia de la partícula terminativa se, que aquí se adjunta a un verbo de actividad y, por lo tanto, léxicamente imperfectivo. Por otro lado, el modo de acción de [Juan cantar una canción] también es perfectivo, a pesar de que el núcleo verbal es un verbo léxicamente imperfectivo; en este caso, no obstante, el factor implicado en la perfección del componente léxico del aspecto es la limitación que introduce el SN objeto una canción en la propiedad léxica del verbo.

7 Existe aquí también la posibilidad de una lectura de conato, según la cual Juan se dormía equivaldría a Juan estaba a punto de dormirse. 


\subsection{Los informantes no nativos (INN)}

Los sujetos no nativos seleccionados como informantes para comprobar las hipótesis planteadas en este trabajo (vid. infra) son aprendices de ELE en contexto institucional. A través de alguna de las redes de intercambios que mantiene España con otras universidades europeas y estadounidenses, estos aprendices de ELE recibían instrucción formal en la Universidad de Barcelona y en la Universidad Pompeu Fabra de la misma ciudad.

Los aprendices de este trabajo constituyen una tipología muy concreta de aprendices de ELE: son estudiantes universitarios entre 20 y 30 años que reciben instrucción en contexto institucional en el país de la segunda lengua durante el periodo en que están viviendo en él; como es habitual, llamamos a este contexto de aprendizaje contexto mixto.

El total de INN es de 43. A todos ellos, se les sometió a la prueba de clasificación de competencia en español y se clasificaron en los niveles 2, 3 y 4; más concretamente, de acuerdo con la clasificación presentada en el Marco común europeo de referencia para las lenguas: aprendizaje, enseñanza, evaluación, disponemos de 9 INN del B1; 21, del nivel B2 y 13 del nivel C1.

\subsection{Los informantes nativos (IN)}

El grupo de control seleccionado para este trabajo está formado por 26 informantes nativos. La lengua materna de los informantes del grupo de control es el español y la mayoría reside en Barcelona.

\section{La prueba, una prueba de selección múltiple}

La tarea escogida para la obtención de datos constituye una prueba de selección múltiple. Está formada por varias unidades sintácticas oracionales, cuyas características se describen a continuación. Entre las unidades oracionales, algunas representan los cuatro predicados básicos (predicados estativos, predicados de actividad, predicados de realización y predicados de logro). Aparte de tales predicados básicos, en esta prueba se han incluido unidades que representan predicados cambiados o derivados por la incidencia del valor aspectual y temporal de los marcadores cada $X$ tiempo y durante $X$ tiempo. La presencia de estos elementos pretende servir para comprobar si los informantes nativos y no nativos seleccionan los pretéritos indefinido e imperfecto en función de su concordancia con el modo de acción del verbo o con el del predicado. 
Se desordenaron las unidades de las que consta la prueba con el fin de que los aprendices no reconocieran el criterio seguido para su elaboración.

A partir de los resultados de esta prueba, nos proponemos comprobar si se observa alguna tendencia clara por parte de las producciones nativas en la selección de los morfemas flexivos para los tipos de predicados básicos y cambiados o derivados. Si es así, podremos contrastar el comportamiento no nativo con el nativo, contraste que nos permitirá comprobar si los hablantes no nativos reconocen la incidencia de marcadores temporales y aspectuales como los citados sobre el valor aspectual de la entrada léxica del verbo.

Antes de acabar, cabe comentar que los predicados que componen esta prueba no aparecen en un contexto temporal explícito, lo que nos permitirá comprobar de forma más rigurosa si los aprendices distribuyen los pretéritos indefinido e imperfecto en función del modo de acción del predicado. En efecto, dicha prueba pretende comprobar el papel que desempeña el componente léxico del aspecto en la distribución de los pretéritos indefinido e imperfecto a lo largo de las distintas etapas del desarrollo de las IL analizadas.

\section{Hipótesis}

Por medio de la descripción y el análisis de los resultados de esta prueba pretendemos comprobar las siguientes hipótesis específicas en torno a las condiciones que guían la elección de los pretéritos indefinido e imperfecto:

a. El uso de los pretéritos indefinido e imperfecto por parte de los aprendices principiantes adultos de español está relacionado con el valor aspectual contenido en la entrada léxica del verbo. Si ello es así, debería observarse una clara tendencia a asociar el indefinido con verbos léxicamente perfectivos (logros y realizaciones como, por ejemplo, "ganar" e "ir a", respectivamente); y el imperfecto con verbos léxicamente imperfectivos (estados y actividades como ser o estar y nadar o correr, entre otros). Suponemos, además, que esta asociación va a decrecer conforme los aprendices reconozcan la incidencia de otros componentes del predicado sobre la propiedad aspectual contenida en la entrada léxica del verbo, lo que nos lleva a proponer la siguiente hipótesis:

b. Cuando los aprendices dispongan de un mayor nivel de conocimiento del funcionamiento del español, la proporción de pretéritos indefinidos e imperfectos no deberá diferir enormemente entre nativos y no nativos, en la medida en que su comportamiento reflejará el reconocimiento de la incidencia de marcadores aspectuales cada $+S N$ temp. y durante $+S N$ temp. sobre el valor aspectual de la raíz del verbo. Por último, 
c. Si los aprendices muestran desviaciones en el uso de estos dos tiempos, éstas reflejarán que todavía afloran criterios aspectuales de nivel léxico.

Gracias a trabajos nuestros anteriores, en los que se ha analizado y valorado la participación de ciertas propiedades sintagmáticas del argumento interno del verbo (Güell, 2008) así como la de la partícula terminativa se (Güell, 2009) en la composicionalidad del aspecto del enunciado, estamos en disposición de matizar dichas hipótesis generales en los términos siguientes:

d. Cuando el contexto lingüístico no aporta información temporal, los informantes nativos distribuyen los pretéritos indefinido e imperfecto de acuerdo con el modo de acción del predicado.

e. En el nivel Bl empiezan a reconocer que la información aspectual con la que concuerdan los pretéritos indefinido e imperfecto no es exclusivamente la contenida en la raíz verbal ${ }^{8}$;

f. en el nivel B2, sin haberse establecido de forma clara, los aprendices reconocen en mayor medida la naturaleza composicional del aspecto así como los factores lingüísticos que participan en dicha composicionalidad 9 ; por último,

g. en el nivel Cl se observa una clara coincidencia entre el uso de los pretéritos indefinido e imperfecto en cuanto expresiones temporales y el uso de estos dos pretéritos para marcar la "concordancia" entre estas dos formas verbales y el componente léxico del aspecto.

\section{La intervención de los marcadores aspectuales en la composición del modo de acción del predicado}

Como otros factores, los marcadores aspectuales también son susceptibles de colaborar en la composición del modo de acción de un predicado. Así, por ejemplo, sintagmas como cada $+S N$ o durante $+S N$ son marcadores aspec-

8 Por un lado, los aprendices del nivel Bl detectan que la información aspectual con la que tienden a concordar dichos pretéritos tiene que ver con la unidad [V + OD]; no reconocen, no obstante, que el mecanismo activo en la composición del valor aspectual del conjunto no es la presencia o no del argumento interno, sino ciertas propiedades sintagmáticas del SN objeto (vid. Güell, 2008). Por otro lado, no reconocen la participación de la partícula terminativa se en la composicionalidad del valor aspectual del enunciado (vid. Güell, 2009).

9 Nos referimos concretamente al reconocimiento de la incidencia de la partícula terminativa se en la composición del modo de acción del predicado y a que son conscientes de que el papel del argumento interno del verbo sobre el valor léxico aspectual de la raíz del verbo tiene que ver con sus propiedades sintagmáticas (vid. Güell, 2008, 2009). 
tuales que introducen en el predicado una interpretación imperfectiva y perfectiva, respectivamente. Así parece ocurrir en (1) y (2):

(1) a. Cada dos años, Vicente ganólganaba un premio.

b. Antonio paseólpaseaba por el parque cada día.

c. Los martes, el profesor de matemáticas paseó/paseaba por la playa.

En (la) el núcleo verbal léxicamente perfectivo (ganar) cuyo argumento interno es un SN delimitado ("un premio") aparece combinado con el marcador aspectual cada dos años. En (la), por medio del sintagma cada dos años se expresa la iteración del acontecimiento designado por ([ganar un premio]). Con ello, por un lado, el predicado es léxicamente imperfectivo y, por el otro, lleva a suponer la existencia de un intervalo de tiempo no delimitado y aquí implícito que incluya temporalmente la iteración de [ganar un premio].

Lo mismo o algo parecido ocurre en ( $1 \mathrm{~b})$, donde el núcleo verbal léxicamente imperfectivo ([pasear]) se combina con el SN iterativo cada día, y en (1c), unidad en la cual la repetición del acontecimiento verbal [pasear por la playa] se expresa por medio de los martes, SN equiparable a cada martes.

(2) a. Durante el verano, mi hermano perdió/perdía la cartera.

b. Vicente ganó/ganaba un premio durante el verano.

c. Luis llevólllevaba sombrero durante las vacaciones.

d. Juan vivió/vivía durante seis meses en Madrid.

En los predicados de todas las unidades de (2) aparece el marcador aspectual durante $+S N$. Los predicados de (2a,b) se distinguen de los de (2b,c), no obstante, por el hecho de que los verbos de los primeros son léxicamente perfectivo (perder y ganar), mientras que los de ( $2 b, c)$ son léxicamente imperfectivos (llevar, en su acepción estativa, y vivir). Ahora bien, tanto en $(2 \mathrm{a}, \mathrm{b})$ como en $(2 \mathrm{c}, \mathrm{d})$, el marcador durante $+\mathrm{SN}$ introduce una lectura delimitada, perfectiva, del enunciado.

A continuación, describimos el comportamiento nativo y el no nativo en lo que se refiere a la asociación de los pretéritos indefinido e imperfecto con unidades sintácticas oracionales en cuyos predicados aparecen marcadores aspectuales como los citados, susceptibles de intervenir en el valor aspectual del conjunto.

\section{Descripción y análisis de los resultados de la prueba de obtención de datos}

Antes de centrarnos específicamente en los datos obtenidos para este trabajo, cabe establecer el punto de partida. A saber, cuando la única información presente en el enunciado es el valor aspectual expresado léxicamente es 
en dicho valor en el que se apoyan los informantes tanto nativos como no nativos a la hora de distribuir el pretérito indefinido e imperfecto. En efecto, en Güell (2009: 6-10) se muestra cómo los informantes nativos asocian de forma clara los pretéritos indefinido e imperfecto con los predicados perfectivos e imperfectivos básicos. Por su parte, desde el nivel B1, también los informantes NN tienden a la misma asociación.

Nos proponemos valorar, seguidamente, el reconocimiento de la incidencia de los marcadores aspectuales cada $+S N$ y durante $+S N$ sobre el valor de la entrada léxica del verbo.

\subsection{CADA + SN. Los resultados nativos}

El análisis cuantitativo de los resultados con respecto a unidades como las de (1) y (2) y otras similares (en total, son 8 unidades, cuatro con la estructura [V léxicamente perfectivo $+\mathrm{SN}$ iterativo] y cuatro con la estructura [V léxicamente imperfectivo $+\mathrm{SN}$ iterativo $])^{10}$ es el que podemos ver en (3)

(3)

\begin{tabular}{|l|c|}
\cline { 2 - 2 } \multicolumn{1}{c|}{} & $\mathrm{N}$ \\
\hline Indef. & 0 \\
\hline Imperf. & 100 \\
\hline
\end{tabular}

CUADRO 1. Asociación de los pretéritos indefinido e imperfecto con prediados en los que aparecen marcadores aspectuales de iteración. Informantes nativos

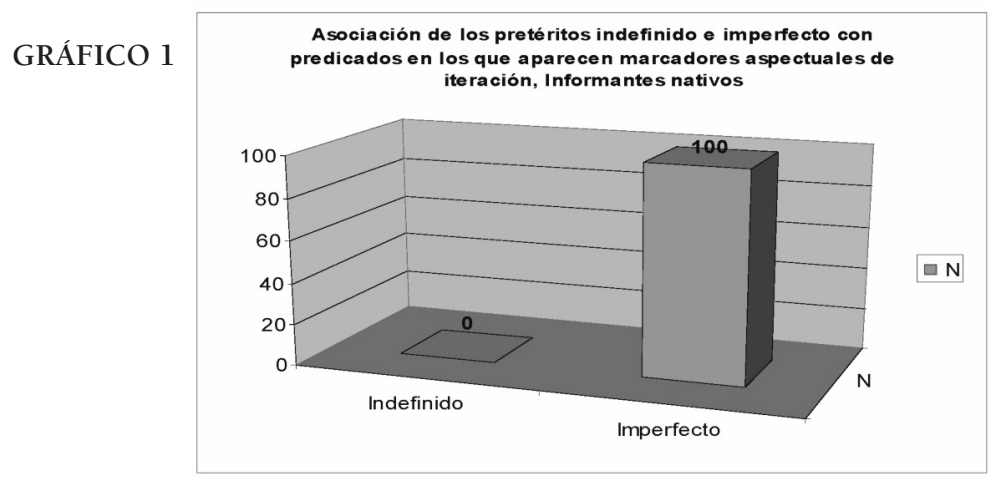

10 Entre las unidades perfectivas, aparte de los verbos léxicamente perfectivos también hemos contabilizado los resultados correspondientes a unidades como, por ejemplo, El niño dibujó/dibujaba un dinosaurio cada día, en las que la imperfección léxica del verbo (aquí, dibujar) queda limitada por el valor delimitado del argumento interno (aquí, un dinosaurio). 
donde el 100\% de los informantes nativos selecciona el imperfecto. En efecto, al margen de que el núcleo verbal del predicado sea léxicamente perfectivo o imperfectivo y de que el marcador aspectual iterativo aparezca en primera posición como en (la, c) o en posición final como en (lb), todos los nativos que se han sometido a esta prueba seleccionan el imperfecto.

De acuerdo con el hecho de que la iteración del acontecimiento expresado por el verbo o por la unidad [V + SN objeto] supone la existencia de un intervalo de tiempo implícito, son sintomáticos los resultados nativos correspondientes a la siguiente unidad:

(4) La semana pasada, Antonio paseólpaseaba por el parque cada día.

A diferencia de lo que hemos visto que ocurre con predicados como los de (1), el $50 \%$ de los informantes nativos asocia el indefinido con el predicado de (4) y el $50 \%$ el imperfecto. Pues bien, dado que la única diferencia entre unidades como las de (1) y la (4) es la presencia del SN temporalizado la semana pasada, que expresa un intervalo de tiempo limitado, podemos atribuir, a tal limitación temporal, la extrema variabilidad de los resultados nativos correspondientes a (4). Con ello, creemos que se pone de manifiesto, por un lado, la estrecha relación que mantienen las informaciones temporales y aspectuales que se manifiestan léxicamente y la selección de los morfemas flexivos del verbo; y, por otro lado, que la asociación del imperfecto con unidades como las citadas en (1) por parte del $100 \%$ de los nativos refleja que la presencia del marcador iterativo cada + SN lleva a suponer la existencia de un intervalo de tiempo implícito y sobre todo no delimitado que incluye temporalmente la repetición del acontecimiento expresado por los respectivos predicados.

A continuación nos centramos en la descripción y el análisis de los resultados no nativos correspondientes a unidades como las citadas en (1).

\subsection{Cada + SN temp. . Resultados no nativos}

El análisis cuantitativo de los resultados no nativos correspondientes a las unidades de (1) y otras similares es el siguiente:

\begin{tabular}{||c|c|c|c|c||}
\cline { 2 - 5 } \multicolumn{1}{l|}{} & B1 & B2 & C1 & N \\
\hline \hline Indef. & $52 ' 1$ & $7 ' 8$ & 14 & 0 \\
\hline Imperf. & $47 ' 8$ & $92 ' 1$ & $\mathbf{8 6}$ & $\mathbf{1 0 0}$ \\
\hline
\end{tabular}

CUADRO 2. Asociación de los pretéritos indefinido e imperfecto con prediados en los que aparecen marcadores aspectuales de iteración. Informantes no nativos: análisis de las sucesivas IL 


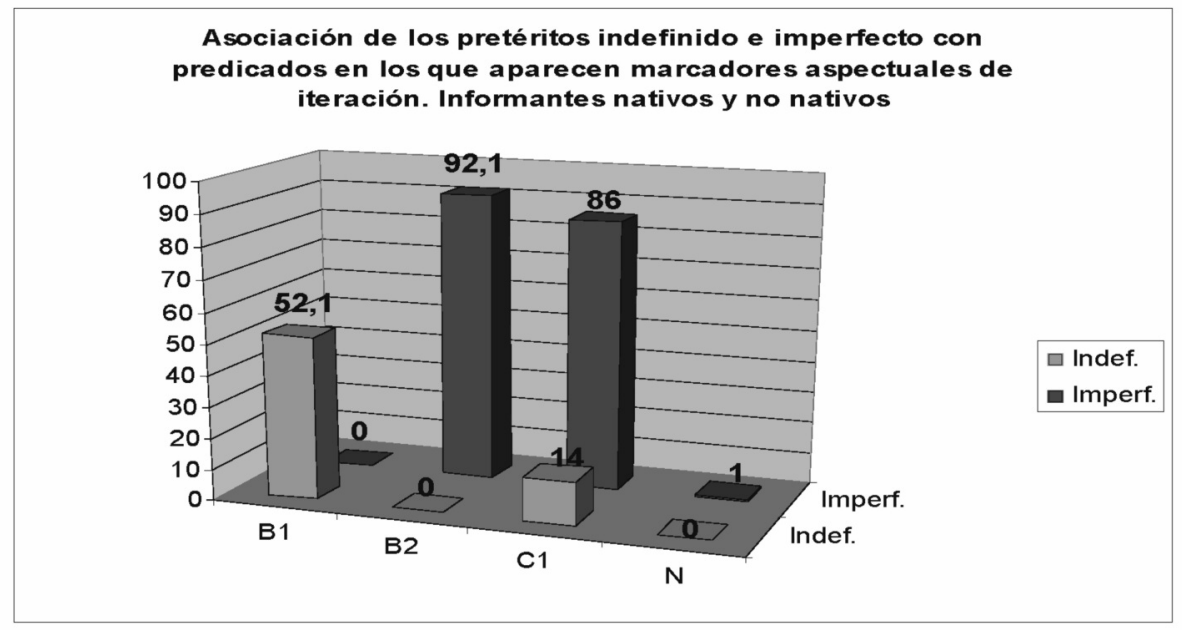

GRÁFICO 2

Estos datos reflejan, por un lado, la progresiva evolución de las sucesivas IL hacia el comportamiento nativo y, por otro lado, que en el nivel Bl se produce una clara vacilación: si en el nivel N1 la proporción de indefinido supera a la de imperfectos en el 4'3\%, en el nivel B2 el porcentaje de imperfectos supera al de indefinidos en el 84'3\%.

La cuestión que debemos plantearnos es si el cambio cuantitativo que se observa entre el nivel B1 y el B2 es producto de un cambio cualitativo o no. Para ello, podemos comprobar si el comportamiento al respecto de los distintos niveles tiene que ver con la clase aspectual de la entrada léxica del verbo. Los resultados son los siguientes:

(6)

\begin{tabular}{|c|c|c|c|c|c|c|}
\hline & \multicolumn{3}{|c|}{ V. perf.+ SN Iterativo } & \multicolumn{3}{|c|}{ V. imp.+ SN Iterativo } \\
\hline & B1 & B2 & C1 & B1 & B2 & C1 \\
\hline Ind. & 70 & $16^{\prime} 6$ & 24 & $38^{\prime} 4$ & $3>8$ & 4 \\
\hline Imp. & 30 & $83 \% 3$ & 76 & $61 \% 5$ & $96 ' 1$ & 96 \\
\hline
\end{tabular}

CUADRO 3-4. Asociación de los pretéritos indefinido e imperfecto con perfectivos e imperfectivos cuyo predicado incluye un marcador aspectual de iteración. Informantes no nativos: análisis de las sucesivas IL 


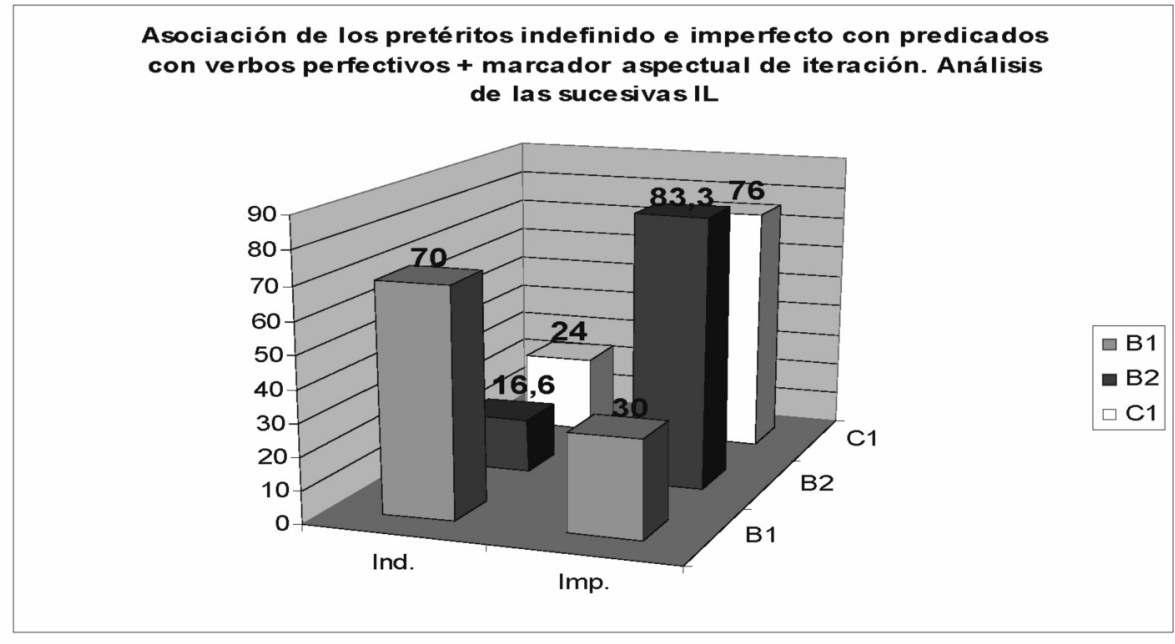

\section{GRÁFICO 3}

Asociación de los pretéitos indefinidoe imperfecto con predicados con verbo imperfectivo + un marcador aspectual iterativo. Análisis de las sucesivas IL
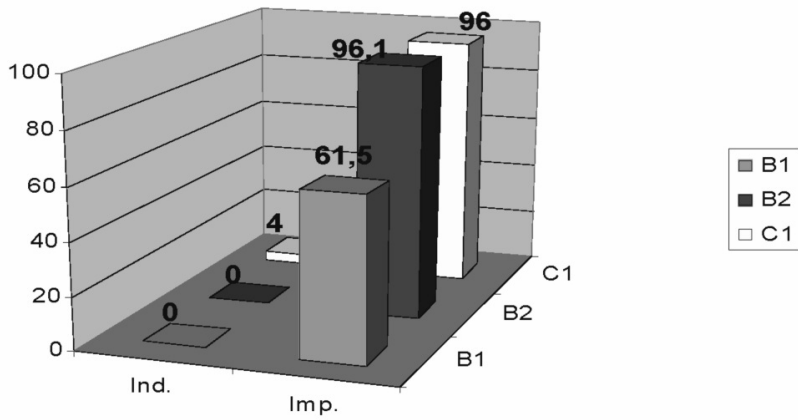

\section{GRÁFICO 4}

Como los informantes nativos, todos los aprendices asocian de forma mayoritaria el imperfecto con el núcleo verbal de los predicados [V. imperf. + SN iterativo $^{11}$. No ocurre lo mismo con las unidades con la estructura [V perf. + SN iterativo]: en estos casos, el $70 \%$ de los $\mathrm{Bl}$ que se han sometido a la prueba opta por

11 En estos casos, no obstante, no podemos saber si la preferencia por el imperfecto se debe a la propiedad aspectual contenida en la entrada léxica del verbo o a la presencia en el predicado del marcador aspectual de iteración. 
el indefinido y el 30\% por el imperfecto. Fijémonos en que esta vacilación de los Bl sugiere que en este nivel la perfección de la entrada léxica del verbo sigue aflorando como criterio de distribución de los pretéritos indefinido e imperfecto. En otras palabras, que los $\mathrm{B} 1$ que se han sometido a la prueba cuyos resultados estamos analizando no reconocen todavía de forma clara la participación del marcador aspectual cada $+S N$ en la composición del modo de acción del predicado.

Tales resultados contrastan de forma clara con los resultados de los B2 y de los $\mathrm{Cl}$, que muestran las mismas tendencias que los nativos. A pesar de ello, la cuestión es si dicha tendencia refleja un comportamiento cualitativo semejante al nativo. Para ello, proponemos valorar los resultados correspondientes a unidades como la de (4) -La semana pasada, Antonio paseólpaseaba por el parque cada día-: si los B2 y $\mathrm{Cl}$ reconocen que los valores iterativo y temporal, que en el predicado de (4) se manifiestan léxicamente, concurren en la composición del modo de acción del predicado, los resultados deberían reflejar cierta vacilación, como hemos visto que ocurre con los datos nativos; ahora bien, si los aprendices analizan a nivel léxico la presencia de cada $+S N$, entonces, los resultados de los $\mathrm{B} 2$ y $\mathrm{Cl}$ deberían ser similares a los presentados en (6).

Los resultados son los siguientes:

\begin{tabular}{||c|c|c|c||}
\cline { 2 - 4 } \multicolumn{1}{c|}{} & $\mathbf{B 2}$ & $\mathbf{C 1}$ & $\mathbf{N}$ \\
\hline \hline Indefinido & $166^{\prime} 6$ & 9 & $\mathbf{5 0}$ \\
\hline Imperfecto & $\mathbf{8 3} \mathbf{3}$ & $\mathbf{9 0}, 9$ & $\mathbf{5 0}$ \\
\hline
\end{tabular}

CUADRO 5. Asociación de los pretéritos indefinido e imperfecto con el núcleo verbal (2). Informantes no nativos

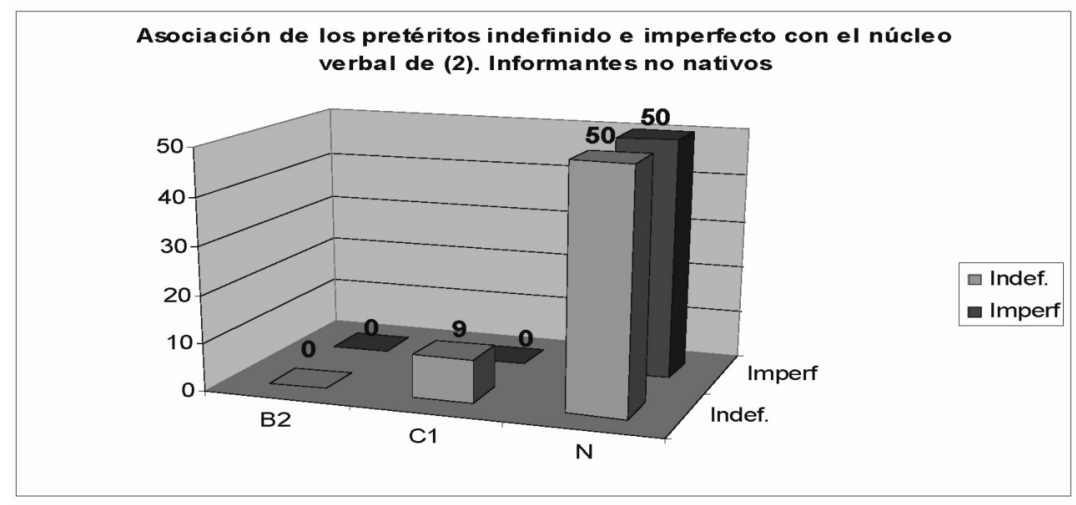

GRÁFICO 5 
Estos datos sugieren que, a diferencia de los nativos, los $\mathrm{B} 2$ y los $\mathrm{Cl}$ seleccionan el imperfecto por la presencia de la expresión iterativa cada $+S N$, que analizan a nivel léxico. No reconocen aún, no obstante, la estrecha relación entre la interacción del tiempo y el aspecto gramaticales, que se manifiestan por medios léxicos, y la selección de los pretéritos indefinido e imperfecto.

\subsection{Cada + SN temp.. Conclusiones parciales}

Los resultados descritos y analizados en este epígrafe ponen de manifiesto que a. los B1 que se han sometido a la prueba no reconocen que marcadores aspectuales de iteración del tipo "Cada + SN temp." constituyan un mecanismo gramatical activo en la composición del modo de acción de un predicado. Así lo pone de manifiesto el hecho de que, al margen de la presencia o no en el predicado de un SN iterativo, sus resultados muestran una clara tendencia a asociar los pretéritos indefinido e imperfecto con los verbos léxicamente perfectivos e imperfectivos, respectivamente.

b. tanto los resultados correspondientes a los $\mathrm{B} 2$ como a los $\mathrm{Cl}$ que se han sometido a la prueba muestran que tales aprendices reconocen la capacidad de los SSNN iterativos de reclasificar el modo de acción del lexema verbal. Su comportamiento refleja, no obstante, que analizan a nivel léxico tales marcadores, como pone de manifiesto que no reconozcan la relación de tal valor aspectual con el tiempo gramatical, relación directamente implicada en la selección de los pretéritos indefinido e imperfecto.

\subsection{DURANTE + SN. Los resultados nativos}

Los resultados muestran que, al margen de las propiedades léxicas del verbo relacionadas con el aspecto, el 81\% de las opciones nativas corresponden al indefinido asociado con el verbo de predicados en los que aparece el marcador aspectual durante $+S N$. Ahora bien, a pesar de que la tendencia nativa se manifiesta de forma clara hacia el indefinido, cabe preguntarse cuáles son las unidades para las que algunos nativos también seleccionan el imperfecto. Son las siguientes:
a. Luis llevó/llevaba sombrero durante las vacaciones.
b. Javier nadó/nadaba durante dos horas.
c. Ana cocinó/cocinaba durante el fin de semana.

Los resultados nativos correspondientes a estas tres unidades concretas son los siguientes: 


\begin{tabular}{||c|c|c|c|}
\cline { 2 - 4 } \multicolumn{1}{l|}{} & $\mathbf{( 8 a )}$ & $\mathbf{( 8 b )}$ & $\mathbf{( 8 c )}$ \\
\hline \hline Indefinido & 40 & $\mathbf{7 7} 7^{\prime} 7$ & $\mathbf{5 5} 5$ \\
\hline Imperfecto & $\mathbf{6 0}$ & $22 ' 2$ & $44^{\prime} 4$ \\
\hline
\end{tabular}

CUADRO 6. Asociación de los pretéritos indefinido e imperfecto con las unidades (8a-c). Informantes no nativos

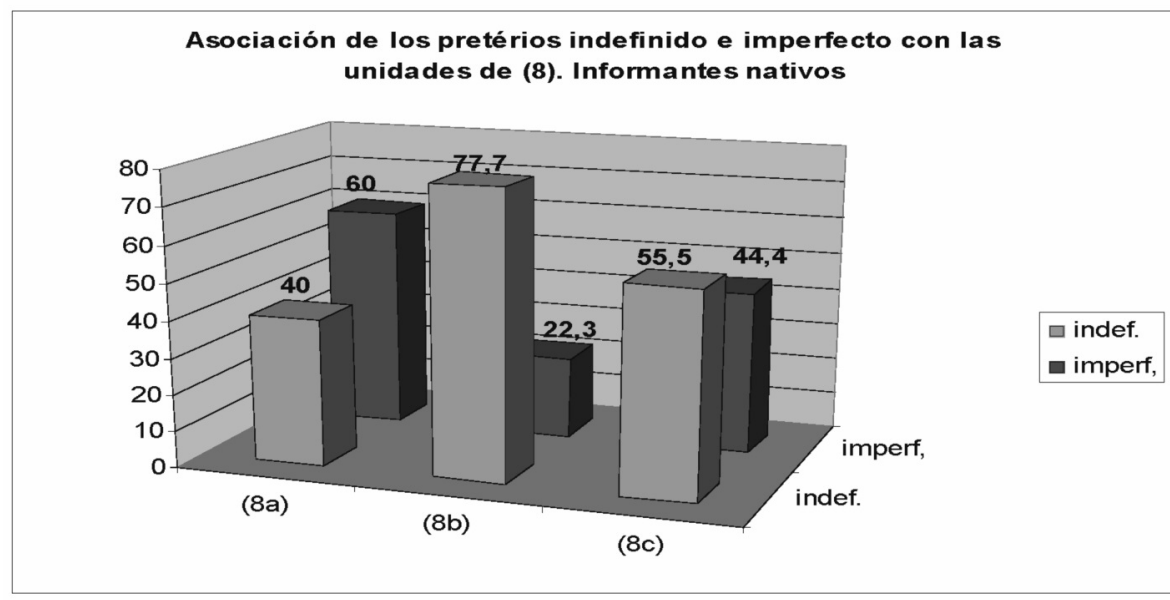

\section{GRÁFICO 6}

Como vemos en (9), los informantes nativos asocian de forma preferente el imperfecto con (8a), lo que contrasta con la tendencia hacia el indefinido para (8b); por último, para la unidad (8c), si bien los resultados se inclinan hacia el indefinido, la preferencia por este tiempo verbal en contraste con el imperfecto sólo es del 11'1\%.

Dado que el núcleo verbal de los predicados de (8) es léxicamente imperfectivo, podríamos pensar que éste es el mecanismo lingüístico que explica la asociación con ellos del imperfecto. Ahora bien, los resultados correspondientes a (8c) y, en mayor medida aún, los de (8b) desmienten tal posible explicación. Además, el 100\% de los nativos asocia el indefinido con el verbo léxicamente imperfectivo de (2d): Juan vivió/vivía durante seis meses en Madrid.

Es probable que los informantes nativos que asocian el imperfecto con las unidades (8a-c) supongan la iteración del acontecimiento expresado por las unidades [llevar sombrero durante las vacaciones], [nadar durante dos horas] y [cocinar durante el fin de semana], respectivamente. Para ello, no obstante, deben 
suponer la existencia implícita de un intervalo de tiempo no delimitado susceptible de incluir temporalmente la repetición de tales acontecimientos. Pues bien, con el fin de comprobar esta posible explicación, hemos analizado cuantitativamente las soluciones nativas correspondientes a unidades como la siguiente:

(10) a. El año pasado Pedro vivió/vivía en Barcelona durante seis meses. b. Ayer Antonio cantó/cantaba durante media hora.

Fijémonos en que en (10a) no es posible suponer la repetición de [vivir en Barcelona durante seis meses], dado el valor del SN temporalizado el año pasado. En (10b), por otro lado, si bien es posible la repetición de [cantar durante media hora] en el intervalo de tiempo expresado por ayer, la presencia de este adverbio temporalizado, que designa un intervalo de tiempo delimitado, nos informa sobre el marco temporal en el que se sitúa el acontecimiento expresado por [cantar durante media hora].

Pues bien, para éstas y otras unidades similares, el 100\% de los nativos selecciona el indefinido, lo que contrasta con los resultados presentados en (9). De acuerdo con ello, podemos suponer que la asociación del imperfecto con unidades como las de (9) por parte de los informantes nativos responde a la posibilidad que presentan los contextos correspondientes de suponer la existencia de un intervalo de tiempo no delimitado que incluya la repetición de los respectivos acontecimientos expresados por la unidad "[V (+ OD) + durante + SN]".

A continuación nos centramos en la descripción y el análisis de los resultados no nativos correspondientes a estas unidades.

\subsection{Durante + SN temp. Resultados no nativos}

Los resultados no nativos correspondientes a la asociación de los pretéritos indefinido e imperfecto con unidades como las citadas en (2) y otras similares (se trata de 9 unidades en total, en 3 el verbo es léxicamente perfectivo y en 6 es imperfectivo) es el siguiente:

(11)

\begin{tabular}{||c|c|c|c|c||}
\cline { 2 - 5 } \multicolumn{1}{c|}{} & $\mathbf{B 1}$ & $\mathbf{B 2}$ & $\mathbf{C 1}$ & $\mathbf{N}$ \\
\hline \hline Indefinido & $\mathbf{5 0}{ }^{\prime} 7$ & $\mathbf{6 0} 1$ & $\mathbf{6 5}{ }^{\prime} 7$ & $\mathbf{8 1}$ \\
\hline Imperfecto & $49^{\prime} 2$ & $39{ }^{\prime} 8$ & $34{ }^{\prime} 2$ & $18^{\prime} 9$ \\
\hline
\end{tabular}

CUADRO 7. Asociación de los pretéritos indefinido e imperfecto con predicados en los que aparece el marcador aspectual "durante $+S N$ ". Informantes no nativos: análisis de las sucesivas IL 


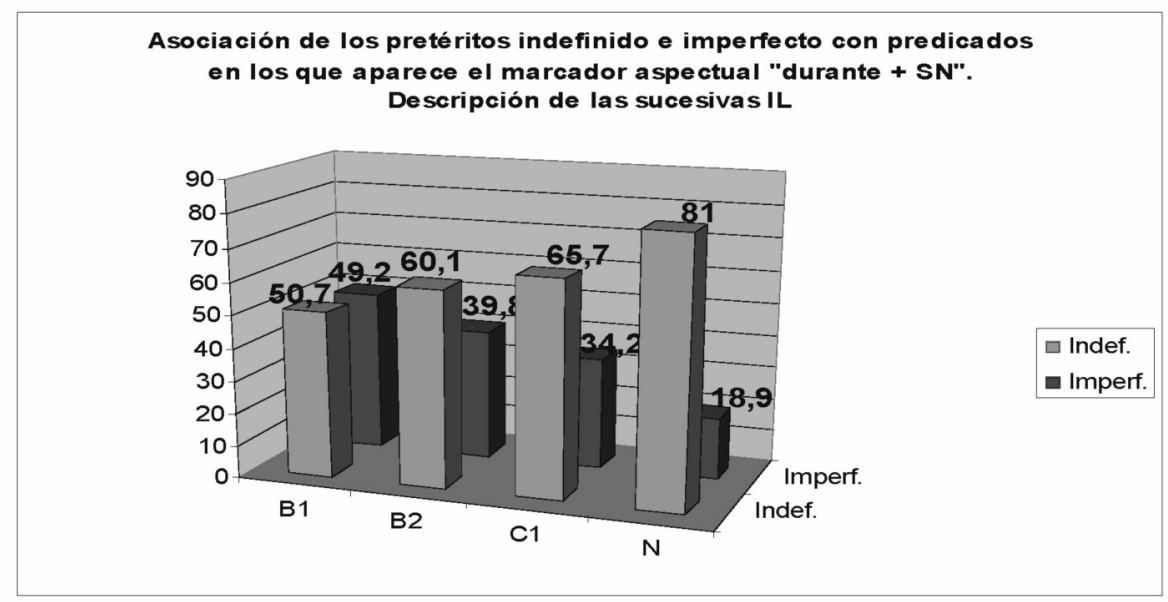

\section{GRÁFICO 7}

Los resultados cuantificados en (11) muestran que los aprendices, desde el nivel 2, asocian el indefinido en mayor medida que el imperfecto con unidades como las de (2). Tal preferencia por el indefinido, no obstante, es inferior a la que reflejan los resultados nativos: la superioridad del indefinido sobre el imperfecto en el nivel B1 es del 1'5\%; en el nivel B2, asciende hasta el 20'3\%; en el nivel C1, llega al 31'5\% y en los nativos es del 62'1\%. A pesar de que tales resultados muestran la evolución de las sucesivas IL hacia el comportamiento nativo, podemos preguntarnos las causas de dichos resultados. Para ello, planteamos dos hipótesis: o bien los aprendices se basan en la propiedad aspectual contenida en la entrada léxica del verbo, sin tener en cuenta la presencia de durante + SN en el predicado; o bien sí tienen en cuenta la presencia de este marcador aspectual, pero se basan en su valor léxico, lo que les lleva a suponer que este marcador aspectual favorece la imperfección del modo de acción del predicado.

De acuerdo con estas dos posibles explicaciones, si los aprendices se basan en el valor aspectual de la raíz verbal, debería observarse una clara tendencia a presentar en indefinido los verbos léxicamente perfectivos que aparecen junto a durante $+S N$ y, en imperfecto los verbos imperfectivos en las mismas condiciones. En cambio, si los aprendices han reconocido la incidencia de este marcador sobre la propiedad aspectual contenida en la entrada léxica del verbo, pero le atribuyen valor imperfectivo, entonces los resultados deberían mostrar una clara tendencia hacia el imperfecto tanto en el caso de que el núcleo verbal sea léxicamente perfectivo como imperfectivo. Veamos el análisis cuantitativo de los resultados desde esta perspectiva: 


\begin{tabular}{|c|c|c|c|c|c|c|}
\hline \multirow[t]{2}{*}{ (12) } & \multicolumn{3}{|c|}{ V perf. + "durante + SN temp." } & \multicolumn{3}{|c|}{ V Imp. + "durante + SN temp." } \\
\hline & B1 & B2 & $\mathbf{C 1}$ & B1 & B2 & C1 \\
\hline Indef. & $72 ’ 7$ & 7299 & $89 ? 7$ & $39^{\prime} 5$ & $51 ' 4$ & $52 ' 7$ \\
\hline Imperf & $27 ’ 2$ & 27 & $10^{\prime} 2$ & $60 \% 4$ & 48,5 & $47^{\prime 2}$ \\
\hline
\end{tabular}

CUADRO 8-9. Contraste entre predicados con la estructura [V perfectivo + "durante+ SN temp."] y predicados con la estructura [V imperfectivo + "durante+ SN temp."].

Informantes no nativos: análisis de las sucesivas IL

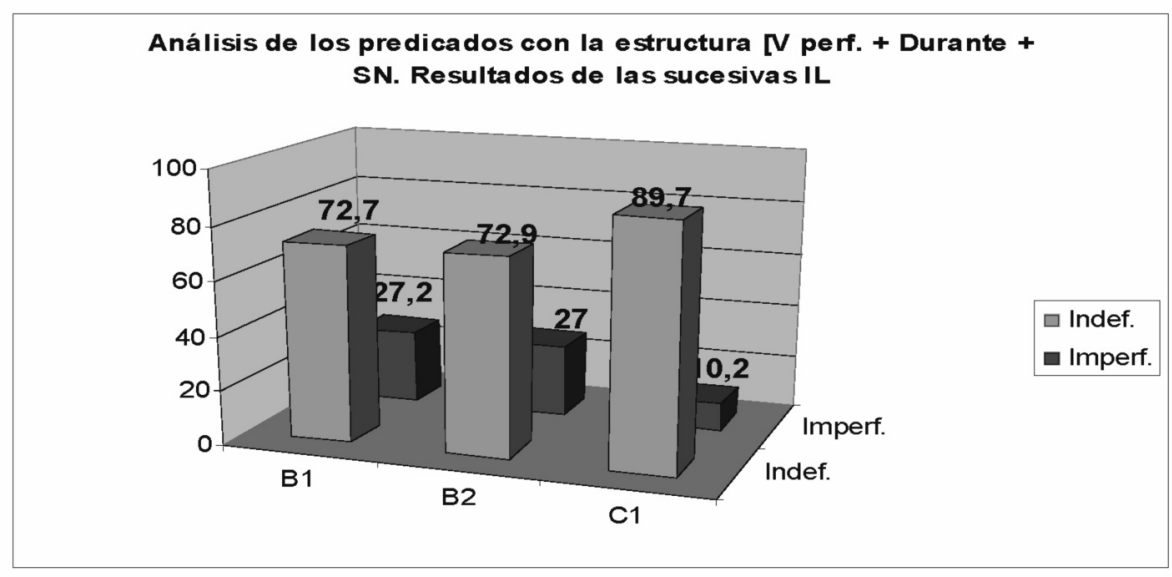

\section{GRÁFICO 8}

\section{Análisis de los predicados con la estructura [V imperf. + Durante + SN]. Resultados de las sucesivas IL}

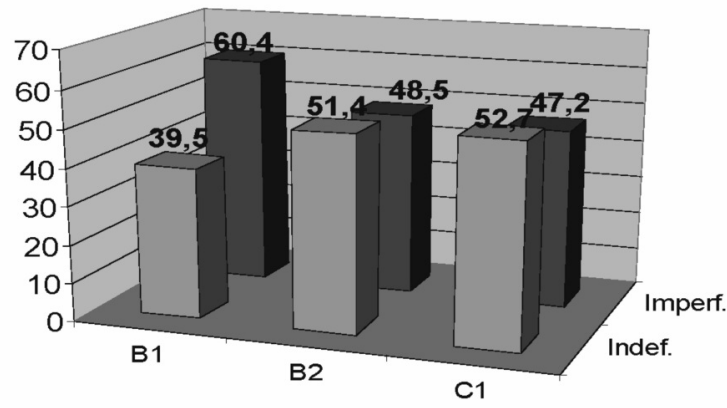


Estos resultados muestran una clara tendencia a asociar el indefinido con los verbos léxicamente perfectivos y, en menor medida, también el imperfecto con los verbos léxicamente imperfectivos.

Tal constatación sugiere que, para unidades como las que analizamos, los aprendices que se han sometido a la prueba se basan en la propiedad aspectual contenida en la entrada léxica del verbo o, dicho de otra forma, que no reconocen la participación del marcador aspectual de perfección durante + SN temp. en la composición del modo de acción del predicado. En líneas generales, ésta es la primera lectura que se desprende de los datos de (12).

Ahora bien, no podemos pasar por alto los resultados de los aprendices del B2, en los que se observa un claro descenso del porcentaje de indefinidos asociados con los verbos léxicamente perfectivos y del imperfecto con los verbos léxicamente imperfectivos. Podríamos suponer que estos datos reflejan que en el nivel B2 se empieza a reconocer que el marcador durante + SN participa en la composición del modo de acción del predicado.

Si los resultados confirman esta explicación, entonces deberíamos suponer que para seleccionar los pretéritos indefinido e imperfecto en estas estructuras ([V. perf/imperf. + durante $+S N]$ ), los aprendices del nivel Bl se apoyan en la propiedad aspectual contenida en la entrada léxica del verbo sin tener en cuenta la presencia del marcador aspectual de perfección durante $+S N$; en el nivel B2, los aprendices reconocen la intervención de este marcador sobre la propiedad léxica del verbo, pero sin reconocer el valor concreto que éste introduce en el predicado; en el nivel $\mathrm{Cl}$, por último, los aprendices empiezan a reconocer que durante $+S N$ introduce valor de perfección en el predicado.

Pues bien, para comprobar la validez de esta posible explicación, proponemos basarnos en los resultados correspondientes a la unidad (2d) y las de (10a-b), que repetimos en (13) y (14), respectivamente:

(13) Juan vivió/vivía durante seis meses en Madrid.

(14) a. El año pasado, Pedro vivió/vivía en Barcelona durante seis meses. b. Ayer Antonio cantó/cantaba durante media hora.

De acuerdo con las hipótesis anteriores, debería comprobarse una clara tendencia por parte de los aprendices del nivel Bl a asociar el imperfecto con el núcleo verbal de la oración (13), cierta vacilación entre el indefinido y el imperfecto en el nivel B2, y preferencia por el indefinido en el nivel C1. Por otra parte, los resultados correspondientes a las unidades de (14) deberían mostrar las mismas tendencias, aunque probablemente, en este caso, la preferencia por el indefinido debería ser superior que en las de (13), dada la presencia de los SSNN temporalizados la semana pasada y ayer, respectivamente. 
Los resultados en lo que se refiere a la asociación de los pretéritos indefinido e imperfecto con el verbo léxicamente imperfectivo de (13) son los siguientes:

\begin{tabular}{|c|c|c|c|c|}
\hline (15) & $B 1$ & B2 & C1 & $\mathbf{N}$ \\
\hline Indef. & $22{ }^{\prime} 2$ & $42^{\prime} 8$ & 71'9 & 100 \\
\hline Imperf. & 777 & $57^{\prime} 1$ & $28 ' 5$ & 0 \\
\hline
\end{tabular}

CUADRO 10. Asociación de los pretéritos indefinido e imperfecto con el verbo de la unidad (13). Informantes no nativos: análisis de las sucesivas IL

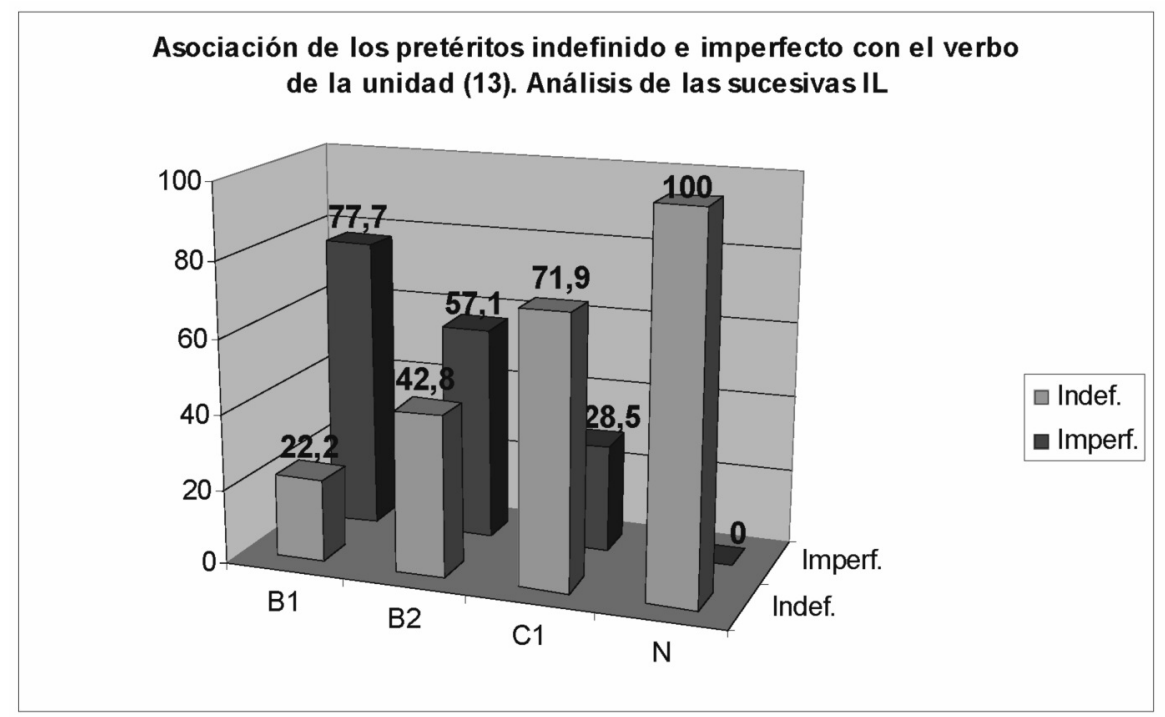

\section{GRÁFICO 10}

Los datos de (15) reflejan que el $777 \%$ de los aprendices del nivel $\mathrm{B} 1$ asocian el imperfecto con la unidad (13); los aprendices clasificados en el nivel B2 también asocian el imperfecto con esta unidad, aunque la preferencia por éste es muy inferior a la que muestran los B1, lo que supone que, aparte de la raíz verbal, los B2 reconocen la intervención de durante + SN en la composición del modo de acción del predicado. Frente a los resultados de estas dos etapas, a pesar de la imperfección léxica del verbo, el 71'9\% de los aprendices del nivel $\mathrm{Cl}$ opta por el indefinido.

Por último, los resultados correspondientes a las unidades de (13) muestran las mismas tendencias: 


\begin{tabular}{||c|c|c|c|c||}
\cline { 2 - 5 } \multicolumn{1}{c|}{} & $\mathbf{B 1}$ & $\mathbf{B 2}$ & $\mathbf{C 1}$ & $\mathbf{N}$ \\
\hline \hline Indef. & 40 & $\mathbf{6 1 , 2}$ & $\mathbf{8 0}$ & $\mathbf{1 0 0}$ \\
\hline Imperf. & $\mathbf{6 0}$ & $38^{\prime} 7$ & 20 & 0 \\
\hline
\end{tabular}

CUADRO 11. Asociación de los pretéritos indefinido e imperfecto con el verbo de unidades de (14). Informantes no nativos: análisis de las sucesivas IL

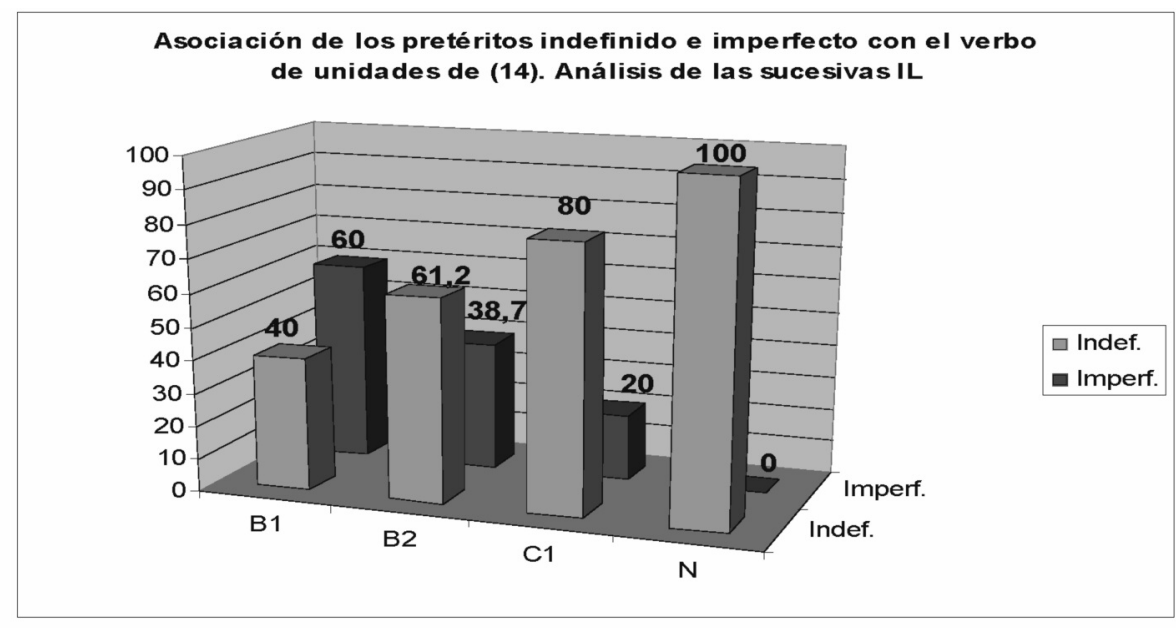

\section{GRÁFICO 11}

Si comparamos estos resultados con los presentados en (15) observamos que aquí aumenta el porcentaje de indefinidos asociados con verbos léxicamente imperfectivos en cuyo predicado aparece el marcador aspectual perfectivo durante + SN . A pesar de ello, no obstante, los B1 siguen prefiriendo el imperfecto. No ocurre lo mismo con las opciones de los B2: si los datos de (15) reflejan cierta vacilación de los B2, los de (16) muestran una clara preferencia por el indefinido por parte de estos aprendices, tendencia que probablemente favorece la presencia de los SSNN temporalizados el año pasado y ayer, respectivamente.

\subsection{Durante + SN temp. Conclusiones parciales}

En resumen, los resultados de (15) y (16) apoyan las hipótesis con respecto a la asociación de los pretéritos indefinido e imperfecto con las estructuras [V perf./imperf. + durante + SN]. Son las siguientes: 
a. Al margen de las propiedades aspectuales contenidas en la entrada léxica del verbo, los resultados nativos muestran una clara tendencia a asociar el indefinido con predicados en los que aparece el marcador aspectual perfectivo durante + SN. Para expresar la iteración del acontecimiento expresado por el predicado [V perf./imperf. + durante $+\mathrm{SN}$ ], los nativos seleccionan el imperfecto. En cualquier caso, a falta de un contexto lingüístico más acotado, la presencia de durante + SN guía la preferencia de los nativos por el indefinido.

b. La preferencia por los pretéritos indefinido o imperfecto por parte de los Bl para estas estructuras responde a la propiedad aspectual contenida en la entrada léxica del verbo; tales aprendices no reconocen, por lo tanto, la participación de durante $+S N$ en la composición del modo de acción del predicado.

c. Aunque tímidamente, en el nivel B2 se empieza a reconocer que tal marcador aspectual perfectivo constituye uno de los factores que componen el modo de acción del predicado. Para tales unidades, además, la preferencia por el indefinido de los B2 es más evidente con la presencia de un marcador temporal delimitado, que favorece el reconocimiento del valor perfectivo de los acontecimientos expresados por medio de predicados con la estructura [V perf./imperf. + durante $+\mathrm{SN}]$.

d. Por último, el comportamiento de los $\mathrm{Cl}$ permite suponer, sin ser evidente, que en esta etapa es más claro el reconocimiento de la incidencia de durante $+S N$ sobre la imperfección léxica del verbo.

\section{Conclusiones parciales relativas al reconocimiento de la incidencia de los marcadores temporales en la composición del modo de acción del predicado}

Los resultados descritos y analizados en este trabajo ponen de manifiesto las siguientes características del comportamiento nativo y el no nativos en lo que se refiere a la asociación de los pretéritos indefinido e imperfecto con el núcleo verbal de predicados en los que aparecen los marcadores aspectuales cada + SN y durante + SN

a. Los resultados de los informantes nativos que se han sometido a la prueba de obtención de datos reflejan una clara tendencia a asociar el indefinido con los predicados cuyo núcleo verbal perfectivo o imperfectivo se combina con el marcador aspectual durante $+S N$; y el imperfecto con predicados en los que aparece el marcador aspectual cada + $S N$. Dado que los resultados nativos permiten suponer que, a falta de 
un contexto temporal explícito, la distribución de los pretéritos indefinido e imperfecto se guía por la clase aspectual del predicado, estos datos indican que estos nativos reconocen la perfección e imperfección léxica que introducen, respectivamente, en el predicado los marcadores durante $+S N$ y cada $+S N$.

En relación con los datos no nativos,

b. los B1 no reconocen la participación de los marcadores aspectuales cada $+S N$ y durante + SN en la composición del modo de acción del predicado. En efecto, la asociación de los pretéritos indefinido e imperfecto con predicados en los que aparece un marcador aspectual como los citados se guía por la propiedad aspectual contenida en la entrada léxica del verbo. Con ello, podemos suponer, por un lado, que los Bl no reconocen la naturaleza composicional del modo de acción del predicado y, por otro, que la distribución de los pretéritos indefinido e imperfecto se guía por criterios aspectuales de raíz léxica (concretamente por la propiedad aspectual contenida en la entrada léxica del verbo).

c. Los resultados de los $\mathrm{B} 2$ y $\mathrm{Cl}$ correspondientes a la estructura $[\mathrm{V}$ perf./imperf.+ SN iterativo] reflejan que los aprendices reconocen la participación de cada + SN en la composición del modo de acción del predicado; limitan, no obstante, la participación de este marcador a nivel léxico, como indica el hecho de que no reconocen las consecuencias temporales de su valor iterativo.

d. Con respecto a las estructuras [verbo perf/imperf + durante $+\mathrm{SN}$ ], los resultados de los B2 reflejan una clara vacilación en lo que se refiere a la asociación con ellas del indefinido e imperfecto; mientras que los de $\mathrm{Cl}$ muestran un tímido reconocimiento de la participación de este marcador aspectual perfectivo en la composición del modo de acción del predicado.

Como hemos comentado antes, aparte de los resultados parciales expuestos anteriormente, contamos con datos empíricos sobre el reconocimiento, por parte de informantes nativos y no nativos, de la incidencia (a) de las propiedades sintagmáticas del argumento interno del verbo en el valor aspectual de la unidad [V + OD], así como de (b) la partícula terminativa se sobre el componente léxico del aspecto. Dado que hemos llevado a cabo dichos estudios desde la misma perspectiva analítica y con el objetivo de valorar las mismas o similares hipótesis, creemos que estamos en disposición de presentar una mirada más amplia sobre los datos resultantes. A ello dedicamos las siguientes líneas. 


\subsection{Conclusiones parciales (2)}

Basándonos en los datos correspondientes a la prueba confeccionada para la obtención de datos, estamos en disposición de establecer algunas conclusiones parciales, que deberían, no obstante, someterse a comprobación en trabajos posteriores. Son las siguientes.

a. Cuando el contexto lingüístico no aporta información temporal, los informantes nativos distribuyen el indefinido y el imperfecto de acuerdo con el modo de acción del predicado. En este sentido, podemos hablar de "concordancia aspectual" entre la flexión verbal y el componente léxico del aspecto, concordancia que, como hemos dicho, no es obligatoria, lo que explica la variabilidad de los resultados nativos.

El comportamiento no nativo muestra las siguientes características:

b. los resultados de los B1 muestran que la distribución de los pretéritos indefinido e imperfecto se rige básicamente por las propiedades léxicas del verbo. No reconocen aún la naturaleza composicional del componente léxico del aspecto (el modo de acción de todo el predicado) que constituye la interacción de las propiedades aspectuales de todas las piezas léxicas que lo organizan. Así lo ponen de manifiesto las siguientes características:

1. los Bl cuyos resultados analizamos en Güell (2009) asocian preferentemente el imperfecto con verbos léxicamente imperfectivos en cuyo predicado aparece la partícula con valor terminativo se. Ello pone de manifiesto que no reconocen la incidencia de dicha partícula sobre el valor aspectual de la raíz verbal;

2. de acuerdo con los resultados analizados en este trabajo, los informantes clasificados en el grupo de Bl no reconocen la participación de los marcadores aspectuales cada $+S N$ y durante $+S N$ en la composición del modo de acción del predicado.

Ahora bien, no podemos dejar de comentar que los resultados de Güell (2008) muestran indicios de que estos informantes reconocen que la información aspectual con la que tienden a concordar los pretéritos indefinido e imperfecto tiene que ver con la unidad [V + OD] y no sólo con las propiedades léxicas del verbo. Estos aprendices no reconocen, no obstante, que el mecanismo activo en la composición del valor aspectual de dicha unidad no es la presencia o no de un $\mathrm{OD}$, sino las propiedades sintagmáticas de tal componente del predicado. 
c. Los datos recogidos relativos a los informantes no nativos clasificados en el grupo de B2 ponen de manifiesto que ya reconocen la naturaleza composicional del componente léxico del aspecto. No reconocen de forma clara, sin embargo, todos los factores implicados en ello. Así lo ponen de manifiesto las siguientes características de sus IL:

1. sin reconocer de forma clara cuáles son las propiedades del argumento interno del V susceptibles de participar en la composición del modo de acción del predicado (vid. Güell, 2008), reconocen que el factor activo en la composición aspectual de la unidad [V + SN objeto] son las propiedades del SN objeto y no sólo la presencia indiscriminada del argumento interno del verbo (Güell, 2008);

2. reconocen la participación de la partícula terminativa se en la composición del modo de acción del predicado (Güell, 2009) y

3. reconocen la participación de cada $+\mathrm{SN}$ en la composición del modo de acción del predicado, pero limitan a nivel léxico la partición de las consecuencias temporales de su valor iterativo. Por otro lado, los resultados muestran una clara vacilación respecto a la incidencia del marcador durante $+\mathrm{SN}$ en la composición del modo de acción del predicado.

d. Respecto a los resultados de los $\mathrm{Cl}$, los datos muestran que en esta etapa

1. los pretéritos indefinido e imperfecto se distribuyen de forma clara de acuerdo con el valor aspectual de la unidad [V + OD] y no sólo con el de la entrada léxica del verbo. Se reconoce también la incidencia de la partícula terminativa se en el valor aspectual del predicado (vid. Güell, 2008, 2009). Por último, los datos muestran 2. un claro reconocimiento de la paricipación del marcador cada + $\mathrm{SN}$ y tímido, de la del durante $+\mathrm{SN}$ en el valor composional del enunciado.

Para acabar, como hemos comentado antes, creemos que las conclusiones a las que hemos llegado con este y otros trabajos deberían (a) ser comprobadas sobre las IL de otros informantes, y (b) analizarse estadísticamente.

\section{Referencias bibliográficas}

Aksu, A. A. (1978): Aspect and Modality in the Child's Acquisition of the Turkish Past Tense. Ph. D. dissertation, University of California, Berkeley. 
Andersen, R.W. (1984b): "The Development of Verbal Morphology in the Spanish of English Speakers". Working draft, Paper prepared at the Temporality Workshop, Max-Planck Institute for Psycholinguistic, Nimegen, Holland (N.P.).

Andersen, R.W. (1985, 1986a): "El Desarrollo de la Morfología Verbal en el Español como Segundo Idioma”. En J.M. Meisel (ed.): Adquisición del Lenguaje. Aquisiçao da linguagem. Frankfurt, Vervuert, págs. 115-138.

Andersen, R. W. (1986b): "Second Language Acquisition of Verbal Aspect" (N.P.).

Antinucci, F. y R. Miller (1976): "How Children Talk about What Happened", Journal of Child Language, 3, págs. 167-189.

Bache, C. (1982): "Aspect and Aktionsart: toward a Semantic Distinction", Journal of Linguistics, 18, págs. 57-72.

Bickerton, D. (1975): Dinamics of the Creole System. London, Cambridge University.

Bloom, L., K. Lifter y J. Hafitz (1980): "Semantics of Verbs and the Development of Verb Inflection in Child Language”, Language, 56/2, págs. 386-412.

Bronckart, J. y H. Sinclair (1973): "Time, Tense and Aspect", Cognition, 2, págs. 107-130. Brown, R. (1973): A First Language: the Early Stages. London, Allen and Unwin.

Bull, W. E. (1971): Time, Tense and the Verb. A Study in Theoretical and Applied Linguistics, with Particular Attention to Spanish. Berkeley, University of California.

Cerny, J. (1970): "El pretérito español y la categoría del aspecto", Actas del XII Congreso Internacional de Lingüística et Filología Románicas, vol. I, págs. 787-792.

Comrie, B. (1976): Aspect. Cambridge, Cambridge University.

De Lemos, C. T. G. (1975): "The Use of ser and estar with Particular Reference to Child Language Acquisition in Brazilian Portuguese". Tesis de doctorado inédita, Universidad de Edimburgo, págs. 99-111.

Dulay, H. C. y M. K. Burt (1974a): "Natural Sequences in Child Second Language Strategies", Language Learning, 24, págs. 37-53.

Dulay, H. C. y M. K. Burt (1974b): "Errors and Strategies in Child Second Language Acquisition", TESOL Quaterly, 8/2, págs. 129-36.

Dulay, H. C. y M. K. Burt (1975): "Creative Construction in Second Language Learning and Teaching". En M. Burt y H. Dulay (eds.): New Directions in Second Language Learning, Teaching and Bilingual Education, Washington D.C., TESOL, págs. 21-32.

Dulay, H. C., M. K. Burt y S. Krashen (1982): Language Two. Rowley, Mass, Newbury House.

Economides, P. J. (1985): The Expression of Tense and Aspect in the English Interlanguage of a Vietnamese Child. Los Angeles, Universidad de California. Tesis doctoral.

Flashner, V. (1982): The English Interlanguage of Three Native Speakers of Russian: Two Perspectives. Los Angeles, Universidad de California. Tesis doctoral.

Gerhardt, J. y I. Savasir (1986): "The Use of the Simple Present in the Speech of Two Three-Year-Olds: Normativity not Subjectivity", Language in Society, vol. 15/4, Cambridge, Cambridge University, págs. 501- 536.

Givón, T. (1982): "Tense-Aspect-Modality: The Creole Prototype and Beyond". En J. Hopper (ed.): Tense-Aspecto: Between Semantics and Pragmatics, Amsterdam, J. Benjamin, págs.115-163. 
Güell, L. (1999): La adquisición del tiempo verbal en el aprendizaje del español como lengua extranjera (http://tesisenxarxa.net/TDX-0629109-131158/)

Güell, L. (2008): "El reconocimiento de la naturaleza composicional del aspecto en la adquisición del español como lengua extranjera" en Actas del XXXVII Simposio Internacional de la Sociedad Española de Lingüística (SEL), editadas por Inés Olza Moreno, Manuel Casado Velarde y Ramón González Ruiz, Departamento de Lingüística hispánica y Lenguas modernas. Pamplona, Servicio de Publicaciones de la Universidad de Navarra, 2008, págs. 271-283. http://www.unav.es/linguis/ simposiosel/actas/

Güell, L. (2009): "Proceso de adquisición de la naturaleza composicional del aspecto en el español como lengua extranjera: el reconocimiento de la incidencia de la partícula terminativa "se" sbre el componente léxico del aspecto", Lingüística en la Red, Universidad de Alcalá de Henares. Publicación electrónica en: http://www.linred.es/ Holiskey, D. A. (1981): "Aspect Theory and Georgian Aspect”. En P. Tedeschi y A. Zaenen (eds.): Syntax and Semantics: Tense and Aspect. New York, Academic, págs. 127-144. Iordan, I. y M. Manoliu (1972): Manual de lingüística románica. Madrid, Gredos.

Jackobsen, T. (1986): “ $i$ Aspecto antes que tiempo? Una mirada a la adquisición temprana del español". En J. M. Meisel (ed.): Adquisición del lenguaje, Frankfurt, Vervuert, págs. 97-114.

Keniston, H. (1936): "Verbal Aspect in Spanish", Hispania, 19, págs. 163-176.

Krashen, S. (1977): "Some Issues Relating to the Monitor Model". En H. Brown, C. Yprio y R. Crymes (eds.): On TESOL 77: Teaching and Learning English as a Second Language: Trends in Research and Practice, Washington, D.C., TESOL.

Kumpf, L. (1982): "Tense, Aspect, and Modality in Interlanguage: A Discourse-functional Approach", Paper presented at the 1982 TESOL convention, Honolulu, Hawaii (N.P.).

Larsen-Freeman, D. (1975): "The Acquisition of Grammatical Morphemes by Adult ESL Learners", TESOL Quaterly, 9, págs. 409-19.

Larsen-Freeman, D. (1976): "An Explanation for the Morpheme Acquisition Order of Second Language Learners”, Language Learning, 26/1, págs. 125-34.

Lyons, J. (1977): Semántica. Barcelona, Teide.

Makino, T. (1980): "Acquisition Order of English Morphemes by Japanese Secondary School Students", Journal of Hokkaido University of Education, 30/2, págs. 101-48.

Meisel, J. M. (1987): "Reference to Past Events and Actions in the Development of Natural Second Language Acquisition". En C.W. Pfaff (ed.), First and Second Language Acquisition Process. Cambridge, Mass, Newbury House, págs. 206-224. Rallides, Ch. (1971): The tense Aspect System of Spanish. Janua Linguarum, Paris, Mouton. Rojo, G. (1973): “Acerca de la temporalidad en el verbo español”, BRAE, 53, págs. 351-375.

Rojo, G. (1974): “La temporalidad verbal en español”, Verba, 1, págs. 68-149.

Rojo, G. (1988): "Temporalidad y aspecto en el verbo español”, LEA, X, págs. 195-216.

Rojo, G. (1990): "Relaciones entre temporalidad y aspecto en español". En I. Bosque (ed.): Tiempo y aspecto en español. Madrid, Cátedra, págs. 17-43. 
Rothstein, G. (1985): The Expression of Temporality in the English Interlanguge of a Native Hebrew Speaker. Los Angeles, Universidad de California. Tesis doctoral.

Silva-Corvalán, C. (1983): "Tense and Aspect in Oral Spanish Narrative", Language, 59, págs. $760-780$.

Smith, C. S. (1983a): "A Theory of Aspectual Choice", Language, 59 (3), págs. 479-501.

Smith, C. S. (1983b): "The Temporal Reference of the English Futurate", Communication and Cognition, 16, págs. 81-96.

Smith, C. S. (1990): The Parameter of Aspect. Austin, Kluwer Academic.

Tedeschi, P. y A. Zaenen (eds.) (1981): Syntax and Semantics: Tense and Aspect. New York, Academic.

Verkuyl, H. (1972): On the Compositional Nature of Aspects. Dordrecht, Reidel.

Verkuyl, H. (1987): "Aspect, Quantification and Negation". En J. Groenendijk, M. Stokhof y F. Veltman (eds.): Proceeding of the 6th Amsterdam Colloquium (Amsterdam), págs. 353-372.

Verkuyl, H. (1989): "Aspectual Classes and Aspectual Composition”, Linguistics and Philosophy, 12, págs. 39-94.

Verkuyl, H. (1990): “A Theory of Aspectuality”, University of Utrecht, 2/5/90, págs. $1-50$.

Verkuyl, H. J. (1993): A Theory of Aspectuality. The Interaction between Temporal and Atemporal Structure. Cambridge, Cambridge University.

Villers, J. y P. De Villers (1973): "A Cross-Sectional Study of the Acquisition of Grammatical Morphemes in Child Speech", Journal of Psycholinguistic Research, 2, págs. 267-278.

Weist, R. H., M. Wytdowska, K. Wikowska-Stadnick, W. Buczowska y E. Konieczna (1984): "The Defective Tense Hypothesis: on the Emerge of Tense and Aspect in Child Polish", Journal of Child Language, 11, págs. 347-374.

Weist, R. M. (1986): "Tense and Aspect". En P. Fletcher y M. Garman (ed.): Language Acquisition. Studies in First Language Development. Cambridge, Cambridge University, págs. 356-374.

Wode, H. (1981): Learning a Second Language. Tubingen, Gunter Narr.

Youssef, V. (1990): "The Early Development of Perfect Aspect: Adverbial, Verbal and Contextual Specification”, Journal of Child Language, 17, págs. 295-312. 